\title{
Medical decisions concerning the end of life for cancer patients in three Colombian hospitals - a survey study
}

Esther de Vries ( $\sim$ estherdevries@javeriana.edu.co )

Pontificia Universidad Javeriana

Fabián Alexander Leal Arenas

Instituto Nacional de Cancerología

Agnes van der Heide

Erasmus MC University Medical Center Rotterdam

Fritz Gempeler

Pontificia Universidad Javeriana

Raul Murillo

Centro Javeriano de Oncología

Olga Morales

Centro Javeriano de Oncología

Eduardo Diaz

Pontificia Universidad Javeriana

Nelcy Rodríguez

Pontificia Universidad Javeriana

Beatriz Juliana Gonzalez

Centro Javeriano de Oncología

Danny Steven Castiblanco Delgado

Universidad Militar Nueva Granada

José Andrés Calvache

Universidad del Cauca

\section{Research Article}

Keywords: End of Life, palliative care, decision making, medical decision, Colombia, cancer, euthanasia, palliative sedation.

Posted Date: March 31st, 2021

DOl: https://doi.org/10.21203/rs.3.rs-288762/v1 
License: (c) (i) This work is licensed under a Creative Commons Attribution 4.0 International License. Read Full License

Version of Record: A version of this preprint was published at BMC Palliative Care on October 18th, 2021. See the published version at https://doi.org/10.1186/s12904-021-00853-9. 


\section{Abstract}

Background: Cancer patients' end-of-life care may involve complex decision-making processes. Colombia has regulations regarding palliative care and is the only Latin American country with legislation regarding euthanasia. We describe medical end-of-life decision-making practices among cancer patients in three Colombian hospitals.

Methods: Attending physicians of 261 cancer patients in participating hospitals answered a questionnaire regarding end-of-life decisions: a.) decisions regarding the withdrawal or withholding of potentially life-prolonging medical treatments, b.) intensifying measures to alleviate pain or other symptoms with hastening of death as a potential side effect, and c.) the administration, supply or prescription of drugs with an explicit intention to hasten death. For each question addressing the first two decision types, we asked if the decision was (partially) made with the intention or consideration that it may hasten the patient's death.

Results: Decisions to withdraw potentially life-prolonging treatment were made for 112 (43\%) patients, 16 of them (14\%) with an intention to hasten death. For 198 patients $(76 \%)$ there had been some decision to not initiate potentially life-prolonging treatment. Twenty-three percent of patients received palliative sedation, $97 \%$ of all patients received opioids.

Six patients (2\%) explicitly requested to actively hasten their death, for two of them their wish was fulfilled. In another six patients, medications were used with the explicit intention to hasten death without their explicit request. In $44 \%(n=114)$ of all cases, physicians did not know if their patient had any advance care directives, $26 \%(n=38)$ of physicians had spoken to the patient regarding the possibility of certain treatment decisions to hasten death where this applied.

Conclusions: Decisions concerning the end of life were common for patients with cancer in three Colombian hospitals, including euthanasia and palliative sedation. Physicians and patients often fail to communicate about advance care directives and potentially life-shortening effects of treatment decisions. Specific end-of-life procedures, patients' wishes and availability of palliative care should be further investigated.

\section{Background}

Colombia, a middle-income country in South America, has experienced a great demographic transition. The country exhibits an increasingly older population due to a transition from a mortality pattern dominated by unnatural causes and communicable diseases towards one dominated by chronic diseases [1]. This growing number of patients dying from chronic diseases has led to the introduction of palliative care in the country, mainly concentrated in hospitals, but slowly spreading towards home care as well [2-4]. Consciousness in society and the medical community at large that end-of-life care for patients with chronic diseases may involve complex decision-making processes, is slowly growing. 
When cure is no longer the main treatment objective for patients with cancer, physicians, patients and family often are faced with making difficult decisions; for example, whether or not to use potentially lifeprolonging medical treatment that is burdensome, risky or with very low probability of success. Decisions may also involve questions on the desirability of extensive diagnostic procedures, surgeries, hospitalization or admission to intensive care units [5]. When cancer patients enter into the last phase of their lives, they often suffer substantially due to pain or other symptoms, or even from the absence of any perspective on improvement. In such end-of-life palliative care situations, decisions need to be made regarding patient comfort [5]. These decisions may affect the remaining duration of the patient's life, their subjective experience during that time or help to address their wishes at the time of death and beyond.

Some patients experience their suffering in the last phase of life as unbearable and ask their doctor for euthanasia. Euthanasia is defined as follows: a physician (or other person) intentionally ending a person 's life by the administration of drugs, at that competent person's voluntary request [6].

Colombia is the only country in South America that has adopted legislation regarding euthanasia (see box 1) [7] - the number of registered euthanasia procedures has risen from 5 in 2015 to 35 in 2019 [8]. The current regulation has been heavily debated, mainly because the offer of palliative care in the country is still very deficient $[2,3]$. A small study showed lack of knowledge among university students regarding euthanasia, but also quite a high degree of acceptance [9]. High quality home- and institution-based palliative care that is available to all is considered paramount in order to ensure that people don't request euthanasia because of insufficient symptom control, lack of access to care or fear of being a burden to caregivers [10]. 


\section{Box 1: The legal status of the application of euthanasia in Colombia in 2017-2020}

In 1997, the Constitutional Court stated the conditions for practicing euthanasia (defined as "murder out of mercy" in the Penal Code) and ruled that under such conditions there would not be any penalty. This was a paradoxical outcome as the Court was solving a case in which a Colombian citizen was requesting to increase the penalty for "killing out of mercy" (six months to three years) to be comparable to homicide (10+ years). In the case of euthanasia, the court acknowledged that the active subject (the doctor) was acting within the criterion of compassion and solidarity, which is enshrined in the Constitution, for the passive subject (the patient). The Court considered that euthanasia must be requested by the patient himself, who must suffer from a terminal illness that causes intense suffering and which cannot be otherwise alleviated. It was established that euthanasia must be carried out by a physician, who would not be penalized if conditions for euthanasia were met (see below).

The treating physician must know the clinical condition of the patient to such extent that a good prediction of prognosis (using prediction scales) is possible in order to define if the patient can be considered terminally ill. A terminally ill patient is defined as a patient with a medically confirmed advanced, progressive and uncontrollable disease, characterized by the absence of reasonable treatment options, with physical and psychological suffering despite having received the best available treatment, and with a life expectancy of less than 6 months.

The following are the processes required to guarantee that patient is capable of requesting euthanasia, regulated in the "Protocol for the application of the procedure of Euthanasia in Colombia" [3]:

1: Medical condition: terminally ill patient. Expected date of death in absence of euthanasia must be established, communicated to the patient and registered in the medical record. Physician must also record if patient is considered to understand his or her medical condition.

2: Evaluation of suffering: nature and level of suffering must be evaluated as "intolerable" and without perspectives of improvement. This evaluation must include the perception of the treating physician and the patients' perception, prioritizing the latter.

3: Absence of alternative treatment or care options. Received interventions must be documented, including those related to symptom management and palliative care and the results of these interventions. The patient must have had contact with a specialist in pain and palliative care and a disease-specific specialist.

4: Persistence of the explicit request. Treating physician informs when was the first time the patient expressed the request and if this request persisted over time for at least 25 days or was repeated and if the request is voluntary, free of influence of others or if any "advance directive", either written or documented in the medical file, exists. 
5: Evaluation of the capacity to decide. A psychiatrist or clinical psychologist must establish the capacity to make decisions of the patient. This evaluation must be performed prior to the evaluation by the euthanasia committee.

6: Second evaluation. The scientific interdisciplinary committee for the right to a dignified death, is the evaluates if the anterior requisites are fulfilled. This committee must be independent from the treating physician (in particular in terms of hierarchy), must not have evaluated the patient previously, and must not have a personal or professional relation with the patient. In case of discordance between the two evaluations, the committee re-evaluates the case consulting another professional.

7: Integrity of the evaluation. The treating physician and the scientific interdisciplinary committee for the right to a dignified death must base their evaluation on the medical records, the document with the written request, the conversation with and physical examination of the patient, and the dialogue with other members of the team of physicians or the family, if the patient authorizes. The treating physician must provide a summary of these findings at the moment of presenting the request for the committee.

Patients and family members or caretakers must be informed on each step of the process and be accompanied by psychologists if needed.

Physicians or medical institutions can refuse to provide euthanasia to a terminally ill patient: physicians can take on conscientious objection and institutions can refuse arguing that their principles are violated, but they have to guide the patient towards a place or situation where their request can be met.

Both adults and children (from 6 years on, meeting certain conditions) are legally allowed to request the procedure.

It is compulsory to send a complete report of the case to the Ministry of Health and Social Protection, which will check the standards of the procedure and provide statistics about it.

We performed a descriptive study to document current practices of medical decisions concerning the end of life, that is, decisions to refrain from potentially life-prolonging treatment and decisions to use (potentially) life-shortening medication of cancer patients in Colombia. This descriptive study describes our findings which can serve as a base for health care professionals, policy-making and the public debate on this very precarious topic.

\section{Methods}

Study design and setting

This cross-sectional survey study was exploratory and descriptive in nature. We documented medical decisions taken during the last month of life of 261 cancer patients who died between May 2019 and 
May 2020 in one of three teaching hospitals: Instituto Nacional de Cancerología (INC), Hospital Universitario San Ignacio (HUSI) and Hospital San José (HUSJ). The first two are located in Bogota, the INC being a specialized and public cancer referral hospital, attending over 7000 new patients per year, and HUSI being a non-profit tertiary hospital - all three hospitals have specialized oncology centers or departments and palliative care teams. HUSJ is a public hospital in a Colombian province, in the city of Popayán, attending the urban population ( $>300,000$ inhabitants) and a large rural area, including several indigenous tribes (guambianos and paéces). Colombia has a mandatory "universal" national social insurance scheme including two main insurance schemes, a contributory one financed by payroll contributions and a subsidized scheme for the poorest population by general taxation. In addition, there are special and exceptional groups which consist of specific types of government workers (public teachers, military, policy and state oil company) with their own schemes [11]. The three participating hospitals attend patients affiliated with different schemes: HUSI mostly attends patients covered under the contributory scheme, while INC and HUSJ attend patients under both schemes as well as patients from special and exceptional schemes.

\section{Participant selection}

Beginning in May 2019 at HUSI, oncological patients who were at the end-of-life were identified by nurses and physicians in participating hospitals, based on functional scales and progressive deterioration of the patients. They notified the research team when a patient who had a life expectancy of less than about 3 months was seen at the outpatient clinic, emergency department or inpatient wards. Research assistants followed-up these patients in hospital and governmental systems for vital status. When these patients deceased, a research assistant assigned a case number to the patient, obtained basic information such as sex, age, type of cancer and type of health insurance (contributive or subsidized, special/exceptional [11]) from the medical file and invited one of the attending physicians to fill out a questionnaire. This physician was selected based on involvement with the patient's care at the end-of-life. The physician was asked to forward the questionnaire to a colleague if they felt the colleague had a better understanding of the decisions surrounding the patient. As a result of this process, it is possible that some physicians answered the questionnaire for more than one patient.

Physicians were further asked to choose the term that they thought best described their act: refraining from treatment, alleviation of symptoms, palliative sedation, withdrawal of futile treatment, respecting advance care directive, assisted suicide, or euthanasia.

\section{Ethics approval and consent, anonymity}

The study protocol was approved by the research ethics committees at Pontificia Universidad Javeriana (number FM-CIE-0086-17) and NCI (Instituto Nacional de Cancerología, number INT-OFI-03581-2019). The physicians answered the questionnaire anonymously, no information on specialization, age, sex or years or experience of the participating physician was collected. Given the very sensitive nature of these decisions, which may sometimes be questionable or go against the policies of individual institution, guaranteeing anonymity of the physicians was key to the success of this project, which implies 
impossibility to request informed consent (which has to be signed with identifying information). The medical ethics committees of the participating institutions studied the situation and approved the study design without signing informed consent, but stating explicitly that participation was voluntary. Each participating institution had a listing of the patient study codes and identifying information, kept by the research assistants, who had no access to the databases. This linking information was destroyed after the data had been collected to ensure anonymity; the researchers did not know the patients' nor the physicians' identifying information. All methods were performed in accordance with the relevant local and international guidelines and regulations.

\section{Statistical analysis}

Variables with an (approximately) normal distribution were summarized as absolute frequencies and proportions, means and SD values, otherwise they were presented as medians and interquartile ranges. All analyses were done in SPSS 25.0 and R [14]. As there were multiple possible combinations of treatment decisions, we summarized combinations (intersections of multiple sets) of decisions by using UpSetR package [15]. The dataset is available as supporting information accompanying this manuscript.

\section{Results}

We identified 348 deceased patients and obtained 261 responses from their physicians (response rate $75 \%)$. The patients for whom we did not obtain a response had a similar age and sex distribution, but included more patients affiliated with the contributive insurance system. Gastric cancer was less common and breast and cervical cancer more common among patients for whom no response was obtained (Supplementary Table 1).

Of the deceased patients for whom we obtained a response from their physicians, the median time in days between death and receiving the questionnaire response was 9 days (IQ interval $6-20$ days), $73 \%$ of these patients died in a hospital, $17 \%$ at home (10\% missing information). Mean age of the patients was 60.2 years (SD 16.3), half of them were females and $54 \%$ were affiliated with the contributive health insurance. Most common cancer types were gastric, breast, and colorectal cancer. The distribution of patients' general characteristics was similar between the participating hospitals, with the exception of type of health insurance and cancer types (Table 1).

Table 1. General characteristics of patients 


\begin{tabular}{|c|c|c|c|c|}
\hline & $\begin{array}{r}\text { Total } \\
\mathrm{n}=261(\%)\end{array}$ & $\begin{array}{r}\text { HUSI } \\
\mathrm{n}=92(\%)\end{array}$ & $\begin{array}{r}\text { INC } \\
\mathrm{n}=143(\%)\end{array}$ & $\begin{array}{r}\text { HUSJ } \\
\mathrm{n}=26 \text { (\%) }\end{array}$ \\
\hline $\begin{array}{l}\text { Age* }(\text { mean } \pm S D \\
\text { median }[\mathrm{IQR}])\end{array}$ & $\begin{array}{l}60.2 \pm 16.3 \\
63[50-72]\end{array}$ & $\begin{array}{r}60.8 \pm 17.1 \\
65[47-72]\end{array}$ & $\begin{array}{l}58.8 \pm 15.9 \\
60[49-70]\end{array}$ & $\begin{array}{l}66.1 \pm 14.9 \\
67[58-76]\end{array}$ \\
\hline $\begin{array}{l}\text { Sex } \\
\text { Male } \\
\text { Female }\end{array}$ & $\begin{array}{l}127(49) \\
134(51)\end{array}$ & $\begin{array}{l}51(55) \\
41(45)\end{array}$ & $\begin{array}{l}63(44) \\
80(56)\end{array}$ & $\begin{array}{l}13(50) \\
13(50)\end{array}$ \\
\hline Top 3 cancer diagnosis & $\begin{array}{r}\text { Gastric } 45(18) \\
\text { Breast } 28(11) \\
\text { Colorectal } 26(10)\end{array}$ & $\begin{array}{r}\text { Gastric } 15(17) \\
\text { Colorectal } 13(15) \\
\text { Breast } 12(13)\end{array}$ & $\begin{array}{r}\text { Gastric } 24 \text { (17) } \\
\text { Breast } 13(9) \\
\text { Colorectal } 12(8)\end{array}$ & $\begin{array}{l}\text { Gastric } 6 \text { (23) } \\
\text { Breast } 3 \text { (11) } \\
\text { Cervical } 2 \text { (8) }\end{array}$ \\
\hline Health care insurance & $\begin{array}{l}\text { Contributive } 141 \text { (54) } \\
\text { Subsidized } 100 \text { (38) } \\
\text { Other \& unknown } 20 \\
\text { (8.4) }\end{array}$ & $\begin{array}{r}\text { Contributive } 89 \text { (97) } \\
\text { Subsidized } 2(2) \\
\text { Unknown } 1 \text { (1) }\end{array}$ & $\begin{array}{r}\text { Contributive } 42 \text { (29) } \\
\text { Subsidized } 87 \text { (61) } \\
\text { Other \& unknown } 14 \\
\text { (10) }\end{array}$ & $\begin{array}{r}\text { Contributive } 10 \text { (39) } \\
\text { Subsidized } 11 \text { (42) } \\
\text { Other \& unknown } 5\end{array}$ \\
\hline
\end{tabular}

*22 missing data (8.5\%): HUSI=6, INC=10, HUSJ=6. HUSI: Hospital Universitario San Ignacio; INC: Instituto Nacional de Cancerología; HUSJ Hospital Universitario San José.

Frequencies of specific end-of-life decisions are summarized in table 2 and combinations of decisions are depicted in figure 1. In almost all cases, management strategies (85\%) were described by physicians as palliative care; $88 \%$ of patients received opioids (Figure 1). In 112 patients (43\%), there had been a decision to withdraw potentially life-prolonging treatment, most frequently for chemotherapy, radiotherapy or nutrition (Figure 1). The decision to withdraw chemotherapy was often combined with the decision to suspend radiotherapy.

Table 2: Frequencies of requests and medical acts related to hastening the end of life as described by physicians

\begin{tabular}{|l|r|}
\hline & frequency \\
& (\%) \\
\hline Requests for active hastening of death & $6(2.2)$ \\
Granted requests for active hastening of death & $2(0.8)$ \\
Assisted suicide / suicide & $0(0)$ \\
Unknown if patient terminated own life & $19(7.2)$ \\
Medical staff formulated a drug with the explicit intention to hasten the end of life of the patient without the & $6(2.2)$ \\
patient's explicit request & \\
\hline
\end{tabular}


Figure $2 \mathrm{~A}$ shows the frequencies of distinct withheld treatment combinations. For the 112 patients for whom treatment withdrawal decisions were made, $16(14 \%)$ were intended to hasten death or noted hastening death as a component in the decision-making process.

For 198 patients $(76 \%)$ there had been some decision to not initiate certain treatments. Of these, not initiating resuscitation maneuvers and tracheal intubation were the most frequent, followed by not initiating hemodynamic support and nutrition. Not initiating resuscitation maneuvers was most frequently combined with not initiating intubation and not initiating hemodynamic support (Figure 2B). There were differences among hospitals in the frequencies of decisions to not initiate treatment (HUSI $77 \%$, INC 71\%, HUSJ 96\%). For 25 (13\%) of the 198 patients for whom decisions not to initiate treatment were made, there was an intention to hasten death. Among these patients, decisions to not initiate resuscitation (93\%) and tracheal intubation (75\%), should they be needed, were frequently made. None of the physicians reported a decision to not initiate hydration among this group.

Twenty-one percent of patients were reported by physicians as having received palliative sedation and $50 \%$ of these patients received artificial hydration during this sedation period.

Six patients (2\%) explicitly requested to hasten their death, and for two of them their wish was fulfilled using medication with the explicit intent to hasten the end-of-life. The medication was administered by nurses in one case and by physicians in the other case. One physician qualified this procedure as euthanasia. The reason for not fulfilling the wish to hasten death in the remaining patients was institutional rejection of applying euthanasia (four patients). Two of these patients submitted the request in another institution but passed away before finishing the procedure. One of these two patients did not have a written request.

Among 6 of the 228 patients who did not request to hasten death (for 27 patients we have no answer for this question), death was caused by the administration of a drug by a medical staff member with the explicit intention to hasten the end of life (or facilitate the patient to end his/her own life). For 19 patients, the physician did not know whether the patient had committed suicide or not.

In $44 \%(n=114)$ of all cases, physicians indicated not to know if their patient had any advance care directives, for $25 \%(n=66)$ they indicated the patient had no directive and for only $7 \%(n=17)$ physicians reported the patient had an advance care directive.

Among the 145 cases where withdrawal of treatment could hasten death, 107 (74\%) were not informed by their physicians regarding this potential effect of hastening death. Physicians indicated they did not speak about this potentially life-shortening effect because 'because the treatment was clearly the best for the patient' $(38 \%, n=55)$; 'the patient was unconscious' $(37 \%, n=53)$ or 'it was not necessary to speak with the patient' $(26 \%, n=37)$. In 28 of the 53 unconscious patients, physicians had a conversation with the spouse or family members of the patient, no conversations took place for the remaining 25 of these patients. 
In $34 \%(n=88)$ of all cases where a decision had been made, there been a conversation with family members regarding the possibility of hastening death as a result of the decision.

\section{Discussion}

The results of this first descriptive, exploratory study regarding treatment decisions at the end-of-life of cancer patients in three Colombian hospitals showed the high frequency of not initiating treatment and withdrawal decisions. Of note, $23 \%$ of patients had palliative sedation prior to their death. According to the physicians, six patients (2\%) requested explicitly to hasten death and for 2 of them, their wish was fulfilled.

While these figures cannot be considered representative for the situation in Colombia in general, they do provide some framework of frequency of certain decisions and of explicit requests to hasten death in this country. There are few studies documenting frequencies of distinct end-of-life decisions and even fewer specifically on cancer (16-18). To our knowledge, no reports with observed data on euthanasia and other types of decisions from South America are available, but there are data from some European countries: of all cancer-deaths in the Netherlands in $2010,41 \%$ of patients had received intensified measures to alleviate pain or other symptoms and $28 \%$ had received 'deep continuous palliative sedation' [13]. In 2007 in Flanders, Belgium and the UK this proportion of palliative sedation was $15 \%$ and $17 \%$, respectively [19]. As we did not provide a very clear definition of "palliative sedation" in our questionnaire, these numbers cannot be directly compared, however, our results (23\% palliative sedation) are in line with these observations. In the Netherlands in 2010, of all sedated patients (including non-cancer deaths), $21 \%$ received artificial nutrition or hydration. This proportion was $2 \%$ among patients treated by family physicians, and went up to $54 \%$ among patients treated by medical specialists (54\%) [12]. It seems that the frequency of applying nutrition and hydration measures ( $50 \%$ of sedated patients) is similar in Colombia as most of our patients were treated by medical specialists. Cultural factors and a relative absence of advance care directives among most terminal cancer patients in Colombia may influence the frequencies of specific end-of-life care decisions. Frequencies may also be somewhat biased because of the overrepresentation of hospital deaths in our study combined with the very limited availability of endof-life care and home-based palliative care in the country [3].

In our study, non-resuscitation and non-intubation decisions were very common. However, it is hard to know whether these decisions were intentions (in case a patient would be candidate for these interventions, would we apply them?) or if they were really executed.

A recent study performed at HUSI-Colombia reports that $70 \%$ of 832 patients who died in this hospital had a do-not-resuscitate order, based on the diagnosis and prognosis of the disease. Only $3.5 \%$ of these do-not-resuscitate orders were established as advance directives, and they were obeyed in $98.3 \%$ of cases [20]. Advance care directives (AD) are formally regulated in Colombia, but their implementation suffers from several problems (see box 2 for details) [21]. Our results show that few patients had advance directives, probably because of relatively little knowledge on the possibility of formulating ADs and lack 
of active information provision [22,23]. However, physicians often did not know whether or not patients had an $A D$ and paternalistic attitudes, legal concerns and cultural and religious factors likely also play a role as was recently observed in a narrative review [24].

\section{Box 2: The legal status advance care directives in Colombia}

The rights of persons at the end of their lives are described in the Resolución 13437 of 1991, in Law 1737 of 2014 and the Resolución 1216 of the $20^{\text {th }}$ of April 2015. Together, these describe the processes and information needed to express an advance directive ("living will"). In article 5 of the Law 1737 of 2014 the rights of patients in the last phases of their lives are described, including the right to sign advance directives, including the right to palliative care; the right to information; to a second opinion; to actively participate in the care processes. Right of children, adolescents and family members are also described. Article 5.4 is dedicated to the right to sign advance directives and described these as follows:

"Any capable, healthy or healthy person disease, in full use of their legal and mental faculties, with full knowledge of the implications that this right carries may sign an advance directive. Whoever subscribes such a document indicate his/her decisions regarding undergoing unnecessary medical treatments that impede a dignified life of the patient and in the event of death the decision regarding organ donation, should this person in the future be suffering from a terminal, chronic, degenerative and irreversible disease with a strong impact on quality of life.

When providing information as part of the medical attention process, physicians are obliged to explain these rights to the patients, including the potential contents of the living will, explanation that the patient can revoke this will at any moment and that neither family members nor members of the medical staff can modify this will when the patient can no longer decide for himself.

Medical-legal experts on the topic have summarized the following barriers to an adequate implementation of advance directives in Colombia: the scarce knowledge in the general population of the right to sign advance directives, the scarce training of healthcare professionals on the subject and the absence of national information systems or national registers of advance directives that are easy to consult by professionals to guide decisionmaking [18].

Decisions not to initiate treatment may be related to medical futility, for example, deciding against fourthline chemotherapy or antibiotic treatments in an imminently dying patient. A study performed in one of the participating hospitals concluded that there had been "disproportional treatments[1]" in $56 \%$ of cancer deaths that occurred in the hospital from 2016-2017, highlighting the need to establish limits on cancer 
treatments. Ideally, medical practice will progress to not consider death as a negative outcome, but rather focus on alleviating suffering and optimizing quality of life and death $[25,26]$. Medical doctors have indicated they have difficulties deciding when to suggest interruption of futile treatments, whereas decisions not to initiate such treatments are more easily made [25].

Decisions to withdraw or withhold "futile" or "non-beneficial" medical interventions should be discussed with the patient and relevant caregivers as problems may arise with patients persisting in their wish for "futile" treatments $[10,27]$. Ideally, all treatment decisions, including non-futile interventions, will involve open and sensitive communication to ensure the patient and their caregivers are adequately informed and understand the implications of the decision. Our data indicate very low levels of communication between physicians and patients on these topics and it seems that in Colombia these decisions are mostly made by the physician ("the doctor knows best"). The six patients who were administered drugs with the explicit intent to accelerate the end-of-life, and did not explicitly request to hasten death (technically considered homicide), could be an example of this. However, these six cases could also reflect confusion among both patients and physicians regarding $A D s$, legal procedures for euthanasia, discussing preferences for different treatment options and other topics surrounding end-of-life care [28]. A qualitative study among healthcare professionals in Colombia showed that physicians sometimes feel an "unspoken desire" to accelerate death but do not really take this "desire" further. The same study also demonstrated the difficulty that physicians have in initiating these discussions and understanding the legal framework. Additionally, it showed that some physicians consider hastening the end of life, even without explicit patient requests, as an act of mercy [29]. Our study found very little conversation takes place between physicians, patients and family members on the dying process and end-of-life decisions, a finding in line with previous studies from countries like the United States and Denmark [30]. It is possible these findings represent a firmly-engrained paternalistic culture which persists among Colombian health professionals. It is also likely that physicians are not well prepared to talk with their patients about death and dying.

Although euthanasia has been depenalized in Colombia for a few years (box 1), the use of this procedure is heavily debated. Many physicians are concerned with the lack of access to palliative care services in the country, citing statements like the one from the European Association for Palliative Care, "If euthanasia is legalized in any society, there should be special attention to avoid the underdevelopment or devaluation of palliative care and conflict between legal requirements and the personal and professional values of physicians and other healthcare professionals" $[10,29]$. In Colombia, access to palliative care services is limited and mostly concentrated in larger cities [2,3], with many pain management specialists being considered palliative care specialists, and very limited attention paid in medical curricula to palliative care in general and end-of-life care specifically. Many healthcare institutions do not offer euthanasia, mostly for religious reasons (many hospitals are catholic institutions). Legally, they are obliged to help facilitate referral of patients to other institutions where euthanasia is performed and they should help initiate the formal process of applying for euthanasia. In reality, many patients may not have the energy and remaining life expectancy to initiate such a trajectory and additionally may not want to 
change institutions. Formally registered cases of euthanasia are rare: only 35 occurred in 2019 in a population of around 49 million inhabitants [8].

There were 19 instances in our study where the physician did not know if the patient had committed suicide. In a simultaneously executed qualitative study regarding the end-of-life decision making process among healthcare professionals, one oncologist mentioned when asked if assisted suicide had ever been requested (translated quote - [29,31]): "No, we have not had this, but I had a patient here who committed suicide [...]- died after his second chemotherapy, at home, woke up dead ... we never knew the cause, but he had no complications... People don't die overnight without having a preamble of a complication. [...] I think that there are people who commit suicide and I think that many people do it because they thought about euthanasia, but people do not access easily, so they commit suicide with an overdose or something." Similarly, this interviewed Colombian patient with end-stage disease mentioned having considered suicide [32]: "Well, why am I going to live like this [..., when it hurts too much. And I can't find ... I feel those things. In fact, the last time I confessed, it was because of that [...] because I had bad intentions, bad thoughts. And I wanted to do it, I don't know why I didn't - Interviewer: Did you want to commit suicide? - Aha [...], but I don't think I'm capable. I think I am not capable. It would be the easiest. But no, I don't know if I'm capable."

The main limitation of the study is its sampling bias. The three participating institutions do, however, exhibit diversity in both the setting (urban versus rural and catholic versus non-Catholic) and socioeconomic classes served (private versus public hospitals with different levels of specializations offered). In order to guarantee anonymity, it was impossible to collect information regarding the specialization, age, years of experience and personal convictions of the participating physicians. It is possible that the deaths of some patients were qualified by the same physician but because of the complete anonymity and invitation procedures, this cannot be confirmed. In patients who had a physician response, the proportion that died in the hospital was higher than the national average ( $73 \%$ in our study versus $68.5 \%$ nationally [33]). We probably did not identify all deaths that occurred at home because the administrative system may be slower in such cases. Additionally, physicians may have been more prone to decline participation in the study for patients who did not die in the hospital as they would be less informed about those patients' end-of-life issues. This overrepresentation of cases who died in hospitals probably increased the proportions of decisions which require hospital environments. Unfortunately, we did not have data on whether or not patients received high-intensity, invasive treatments and there is a lack of data on the character of decision-making processes (shared versus paternalistic). The high proportion of physicians who indicated not to have spoken with the patients 'because the treatment was clearly the best for the patient' (25\%) or 'it was not necessary to speak with the patient' (17\%) seems to indicate that the paternalistic approach is common.

Strengths of this study include the relatively high number of deceased patients and very high participation of invited physicians in the study, although physician non-participation may not have been random and data may have been different had all physicians agreed to participate. Some "non-socially 
desirable" answers were obtained, even some that breach regulations - which seems to indicate that the physicians felt free to report actual events rather than distort their answers to socially desirable ones.

[1] Defined in that study as invasive procedures, surgeries, complex medication, and costly interventions that began or took place during the final hospitalization period of the studied patients.

\section{Conclusions}

In conclusion, all types of end-of-life decisions were being made in the three Colombian hospitals, including palliative sedation and euthanasia. There is a general lack of conversation between physicians and patients regarding wishes, advance care directives and potential life-shortening effects of treatment decisions. Since the primary aim of palliative care is to relieve suffering, it is not possible to provide palliative care without good communication with patients and their families. If physicians and other healthcare professionals do not listen to patients or lack communication skills that allow for understanding of patients' suffering, they run the risk of inflicting further suffering through their decisions despite their best intentions [34]. The findings from this study imply that, although most physicians characterized the care provided to their patients as "palliative care", they provided patients with something else - paternalistic care. In this study's hospitals and possibly in Colombia as a whole (as it likely is in other countries) there are still some fundamental misunderstandings about the meaning of palliative and end-of-life care.

\section{Declarations}

\section{Ethics approval and consent to participate}

The study protocol was approved by the research ethics committees at Pontificia Universidad Javeriana (number FM-CIE-0086-17) and NCI (Instituto Nacional de Cancerología, number INT-OFI-03581-2019). The physicians answered the questionnaire anonymously, no information on specialization, age, sex or years or experience of the participating physician was collected. Given the very sensitive nature of these decisions, which may sometimes be questionable or go against the policies of individual institution, guaranteeing anonymity of the physicians was key to the success of this project, which implies impossibility to request informed consent (which has to be signed with identifying information). The medical ethics committees of the participating institutions studied the situation and approved the study design without signing informed consent, but stating explicitly that participation was voluntary. Each participating institution had a listing of the patient study codes and identifying information, kept by the research assistants, who had no access to the databases. This linking information was destroyed after the data had been collected to ensure anonymity; the researchers did not know the patients' nor the 
physicians' identifying information. All methods were performed in accordance with the relevant local and international guidelines and regulations.

\section{Consent for publication}

Not applicable

\section{Availability of data and materials}

The datasets used and/or analysed during the current study are available from the corresponding author on reasonable request.

\section{Competing interests}

The authors declare that they have no competing interests

\section{Funding}

This study was financed by Minciencias, in the framework of the "777-2017 Convocatoria para proyectos de ciencia, tecnología e innovación en Salud 2017", project CT-826-2018 - Decisiones médicas al final de la vida en pacientes oncológicos en Colombia". Minciencias (Colombian government research funding body) had no role in the design of the study and collection, analysis, and interpretation of data of in writing the manuscript.

\section{Authors' contributions:}

EdV, ED, NR, JAC conceptualised the study; EdV, AvdH, NR, JAC developed the methodology and analytical plan. FAL, BJG, DSCD, JAC undertook data collection and preliminary analysis assisted by RM, OM, FG. JAC, EdV, AvfH, RM, ED, NR and EdV contributed to final analysis and interpretation of the data. EdV, AvdH, JAC, FG, RM and ED drafted the manuscript, all others revised. All authors read and approved the final manuscript.

\section{Acknowledgements}

We are very grateful for the participation of all anonymous physicians who took the time to answer the questionnaires. We would like to thank Natalia Godoy Casasbuenas, Angela Luna Meza, Mauricio Medina Rico, Sandra Liliana Ardila, Angélica Arango and Lucia Ines Arroyo Castillo for their help in patient identification, data collection and critical reading of this manuscript. We would like to thank Brett Will of Georgetown University for the English language revision.

\section{References}


1. Marinho FM, Soliz P, Gawryszewski V, Gerger A. Epidemiological transition in the Americas: changes and inequalities. The Lancet. 2013;381:S89. https://doi.org/10.1016/s0140-6736(13)61343-4

2. Pastrana T, Eisenchlas J, Centeno C, De Lima L. Status of palliative care in Latin America: looking through the Latin America Atlas of Palliative Care. Curr Opin Support Palliat Care. 2013;7:411-416. https://doi.org/10.1097/SPC.0000000000000008

3. Calvache JA, Gil F, de Vries E. How many people need palliative care for cancer and non-cancer diseases in a middle-income country? Analysis of mortality data. Colombian Journal of Anesthesiology 2020;48(4):e924. https://doi.org/10.1097/cj9.0000000000000159

4. Ley 1733 de 2014. Congreso de la República de Colombia. Ley Consuelo Devis Saavedra [http://www.secretariasenado.gov.co/senado/basedoc/ley_1733_2014.html]. Accessed 20 Jan 2021

5. Sharma RK, Cameron KA, Zech JM, Jones SF, Curtis JR, Engelberg RA. Goals-of-Care Decisions by Hospitalized Patients With Advanced Cancer: Missed Clinician Opportunities for Facilitating Shared Decision-Making. Journal of Pain and Symptom Management 2019;58:216-23. https://doi.org/10.1016/j.jpainsymman.2019.05.002

6. Rietjens JAC, Deschepper R, Pasman R, Deliens L. Medical end-of-life decisions: Does its use differ in vulnerable patient groups? A systematic review and meta-analysis. Social Science \& Medicine 2012;74:1282-7. https://doi.org/10.1016/j.socscimed.2011.12.046

7. Gaviria Uribe A, Ruiz Gómez F, Dávila Guerrero C, Burgos Bernal G, Escobar Morales G, Osorio Saldarriaga $\mathrm{E}$, et al. Protocolo para la aplicación del procedimiento de eutanasia en Colombia. Bogotá; 2015 [https://www.minsalud.gov.co]. Accessed 10 Jan 2021

8. Fundación Pro Derecho a Morir Dignamente DMD, Colombia. [https://dmd.org.co/muertedigna/eutanasia]. Accessed 15 Jan 2021

9. Velásquez Portilla M, Espejo-Saavedra A, Navarrete Ospina F, Robledo Gómez S, Salazar Jaramillo M, Baquero García P, Buesaquillo C, Arango L, Burbano L, Andrade L, Calvache JA, De Vries E. Conocimientos acerca de la eutanasia en estudiantes universitarios en dos instituciones de educación superior en Colombia. Univ Med. 2021;62(1). https://doi.org/10.11144/Javeriana.umed62-1.euta

10. Radbruch L, Leget C, Bahr P, Müller-Busch C, Ellershaw J, de Conno F, et al. Euthanasia and physicianassisted suicide: A white paper from the European Association for Palliative Care. Palliat Med. 2016;30:104-116. https://doi.org/10.1177/0269216315616524

11. de Vries E, Buitrago G, Quitian H, Wiesner C, Castillo JS. Access to cancer care in Colombia, a middleincome country with universal health coverage. J Cancer Policy. 2018;15:104-112. https://doi.org/10.1016/j.jcpo.2018.01.003

12. Van der Heide A, Brinkman-Stoppelenburg A, Van Delden H, Onwuteaka-Philipsen B, Sterfgevallenonderzoek 2010 Euthanasie en andere medische beslissingen rond het levenseinde. Den Haag 2010. [https://publicaties.zonmw.nl/]. Accessed 10 Jan 2021

13. Van der Heide A, Onwuteaka-Philipsen BD, Rurup ML, Buiting HM, Van Delden JJM, Hanssen-de Wolf JE, et al. End-of-life practices in the Netherlands under the Euthanasia Act. N Engl J Med. 2007; 
356(19):1957-1965. https://doi.org/10.1056/NEJMsa071143

14. R Core Team (2020). R: A language and environment for statistical computing. R Foundation for Statistical Computing, Vienna, Austria. [https://www.R-project.org/]. Accessed 2 Jan 2021

15. Conway JR, Lex A, Gehlenborg N. UpSetR: an R package for the visualization of intersecting sets and their properties. Bioinformatics. 2017; 33: 2938-2940.

https://doi.org/10.1093/bioinformatics/btx364

16. Sarmiento-Medina MI, Vargas-Cruz SL, Velásquez-Jiménez CM, Sierra de Jaramillo M. Terminally-ill patients' end of life problems and related decisions. Rev Salud Publica (Bogota). 2012; 14 (1): 11628. https://doi.org/10.1590/s0124-00642012000100010

17. Soto-Perez-de-Celis E, Chavarri-Guerra Y, Pastrana T, Ruiz-Mendoza R, Bukowski A, Goss PE. End-ofLife Care in Latin America. J Glob Oncol. 2016; 3(3):261-270. https://doi.org/10.1200/JG0.2016.005579

18. Benavides LLL. The right to die with dignity in Colombia. Forensic Res Criminol Int J. 2018; 6(6):426-429. https://doi.org/10.15406/frcij.2018.06.00239

19. Anquinet L, Rietjens JAC, Seale C, Seymour J, Deliens L, Van Der Heide A. The practice of continuous deep sedation until death in Flanders (Belgium), the Netherlands, and the U.K.: A comparative study. J Pain Symptom Manage. 2012;44:33-43. https://doi.org/10.1016/j.jpainsymman.2011.07.007

20. Gempeler Rueda F, Sanín Hoyos A, Echeverri M, Balocco A, Parra A. Frecuencia de órdenes de no reanimación en un hospital universitario de cuarto nivel de complejidad. Universitas Médica. 2018; 59: 1-10. https://doi.org/http://dx.doi.org/10.11144/Javeriana.umed59-2.rean

21. Bolívar Góez P, Gómez Córdoba Al. Voluntades anticipadas al final de la vida. Una aproximación desde la regulación colombiana y en el derecho comparado. Revista Latinoamericana de Bioética. 2016;16(1):128-153. http://dx.doi.org/10.18359/rlbi.1444

22. Beernaert K, Haverbeke C, Van Belle S, Deliens L, Cohen J. Information needs about palliative care and euthanasia: A survey of patients in different phases of their cancer trajectory. Patient Education and Counseling. 2018;101:132-8. https://doi.org/10.1016/j.pec.2017.06.034

23. He YJ, Lin MH, Hsu JL, Cheng BR, Chen TJ, Hwang SJ. Overview of the Motivation of Advance Care Planning: A Study from a Medical Center in Taiwan. Int J Environ Res Public Health. 2021 Jan 7;18(2):417. https://doi.org/10.3390/ijerph18020417

24. Arruda LM, Abreu KPB, Santana LBC, Sales MVC. Variables that influence the medical decision regarding Advance Directives and their impact on end-of-life care. Einstein (Sao Paulo). 2019 Oct 10;18:eRW4852. https://doi.org/10.31744/einstein_journal/2020RW4852

25. Cuadrado DM. Tratamientos no proporcionados al final de la vida en pacientes fallecidos en un hospital universitario de 4 nivel. Bogota: Pontificia Universidad Javeriana; 2010. [https://repository.javeriana.edu.co/handle/10554/41059]. Accessed 10 Jan 2021

26. Gempeler FE, Torregrosa Almonacid L, Cuadrado DM, Barriga Rodríguez S, Sotomayor Londoño J, Jassir Acosta MP, Filizzola Bermúdez JD, Uribe Rueda D. Intervenciones médicas no proporcionales 
al final de la vida en un hospital de alta complejidad en Colombia. Universitas Médica. 2021;62(1). https://doi.org/10.11144/Javeriana.umed62-1.imnp

27. Armstrong $\mathrm{MH}$, Poku JK, Burkle $\mathrm{CM}$. Medical futility and nonbeneficial interventions: an algorithm to aid clinicians. Mayo Clin Proc. 2014;89:1599-1607. https://doi.org/10.1016/j.mayocp.2014.08.017

28. Beernaert K, Haverbeke C, Van Belle S, Deliens L, Cohen J. Information needs about palliative care and euthanasia: A survey of patients in different phases of their cancer trajectory. Patient Educ Couns. 2018;101(1):132-138. https://doi.org/10.1016/j.pec.2017.06.034

29. Luna Meza A. Toma de decisiones prácticas médicas en el cuidado del final de la vida del paciente terminal con cáncer: un abordaje desde la experiencia del personal de salud. Bogota: Pontificia Universidad Javeriana 2020. [http://hdl.handle.net/10554/50644]. Accessed 18 Jan 2021

30. Bergenholtz H, Timm HU, Missel M. Talking about end of life in general palliative care - what's going on? A qualitative study on end-of-life conversations in an acute care hospital in Denmark. BMC Palliat Care. 2019;18:62. https://doi.org/10.1186/s12904-019-0448-z

31. Luna-Meza A, Godoy-Casasbuenas N, Calvache JA et al. Decision making in the end-of-life care of patients who are terminally ill with cancer - a qualitative descriptive study with a phenomenological approach from the experience of healthcare workers., 01 March 2021, PREPRINT (Version 1) available at Research Square [https://doi.org/10.21203/rs.3.rs-155936/v1]

32. Medina Rico MA. Deseos al final de vida en pacientes con cáncer no curable: un abordaje desde la perspectiva del paciente. Bogota: Pontificia Universidad Javeriana 2021. [[http://hdl.handle.net/XXX]. Accessed 10 Feb 2021

33. Valdivieso J. Analysis of factors associated to the death place among people with cancer diagnosis, from administrative data, 2014-2017, Colombia. Pontificia Universidad Javeriana 2020. [https://repository.javeriana.edu.co/handle/10554/41059]. Accessed 18 Jan 2021

34. Cassel EJ. The Nature of Suffering and the Goals of Medicine. N Engl J Med 1982;306:639-45. https://doi.org/10.1056/nejm198203183061104

\section{Figures}




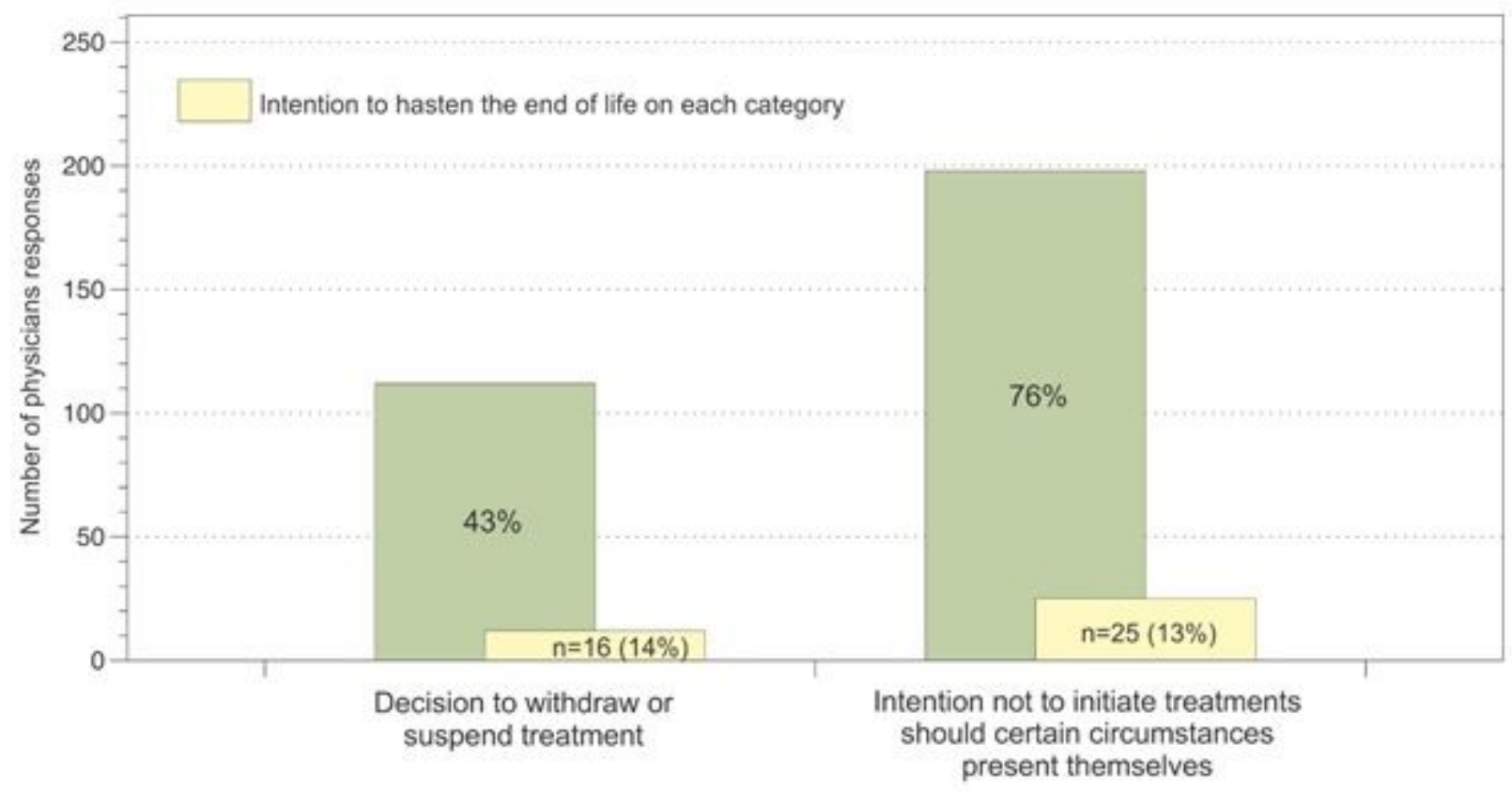

\section{Figure 1}

Medical decisions concerning the end of life of the patient of withdrawing or not initiating treatments $(n=261)$
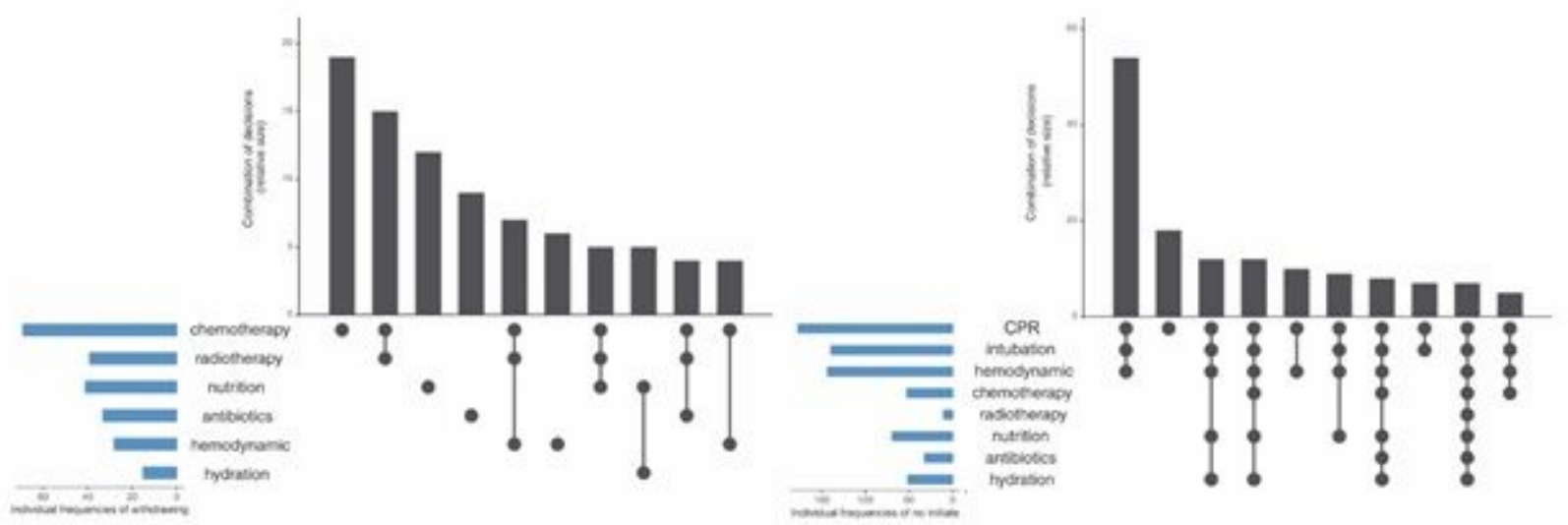

Figure 2

Frequencies and combinations of $(\mathrm{A})$ withdrawing of treatment decisions, and (B) no initiating treatment decisions

\section{Supplementary Files}

This is a list of supplementary files associated with this preprint. Click to download.

- Questionnaireenglish.docx.docx 
- supplementarytable1.docx

Page 21/21 